\title{
Qualidade de Vida e Promoção da Saúde
}

\author{
Pollyanna Nayara Belem Leite ${ }^{(1)}$
}

Resumo: Este estudo teve como objetivo revisar a literatura sobre Qualidade de Vida e Promoção da Saúde. Foram consultados 36 produções entre os livros científicos, revistas e textos, para uma melhor reflexão sobre os conceitos de qualidade de vida. Esses conceitos abordaram vários aspectos, como o trabalho, a saúde, a família e as atividades das pessoas na sociedade. Como resultado, foi possível identificar as ligações entre saúde e condições de vida das pessoas. Também questões relacionadas às políticas públicas em termos de qualidade de vida das pessoas, como um meio de promoção da saúde, através de práticas que podem efetivamente, melhorar a forma como as pessoas em geral vivem. A avaliação adequada da qualidade de vida das pessoas é certamente, uma ferramenta importante, para que possamos discutir uma melhor compreensão da nossa realidade em termos de uma expectativa de vida mais saudável.

Palavras-chave: Qualidade de vida, promoção da saúde, condições de saúde

\section{Quality of Life and Health Promotion}

\begin{abstract}
This study aimed to review the literature on Quality of Life and Promoting Health were consulted 36 productions between scientific books, law journals and texts for better reflection on the concepts of quality of life. Those concepts addressed various aspects such as work, health, family and the activities of people in society. As a result, it was possible to identify links between health, living conditions and ethyl life. Also questions related to the public policy and quality of the life of people, as a means of promoting health through practices that can effectively pass on the improvement of living conditions of people in general. A proper assessment of the quality of life of people, is certainly an important tool that can discuss a better understanding of our reality in terms of a more healthy life expectancy.
\end{abstract}

Keywords: Quality of life, health promotion, health conditions

\section{Introdução}

Para uma melhor compreensão da discussão sobre a qualidade de vida (QV) relacionada à saúde, buscamos discutir, inicialmente, alguns conceitos sobre o tema.

\footnotetext{
${ }^{1}$ Pollyanna Nayara Belem Leite é Enfermeira e Pós-graduanda em Políticas Públicas em Saúde Coletiva pela Universidade Regional do Cariri - URCA. E-mail: pollybelem@yahoo.com.br.
}

Id en line Revista de Psicologia. Ano 7, No. 20, Julho/2013 - ISSN 1981-1179

Edição eletrônica em http://idonline.emnuvens.com.br/id 
Ferreira (1986), em seu importante dicionário Aurélio, adotou como qualidade o seguinte conceito: substantivo feminino abstrato, empregado em nossa língua com diversos sentidos e significados; disposição moral ou intelectual das pessoas, o seu dote, o dom, a virtude, um atributo, uma propriedade, uma condição das coisas ou pessoas, capaz de distingui-las uma das outras e de lhes determinar a natureza, escala de valores, que permite avaliar e, consequientemente, aprovar, aceitar, ou recusar qualquer coisa.

O Mesmo dicionário Aurélio, relaciona, como primeiro de uma série, o seguinte significado para a palavra vida: Conjunto de propriedades e qualidades graças às quais animais e plantas, ao contrário dos organismos mortos ou da matéria bruta, se mantém em contínua atividade, manifestada em funções orgânicas tais como o metabolismo, o crescimento, a reação a estímulos, a adaptação ao meio, a reprodução, modo de viver. E ainda expressa que vida pode ser o que representa para alguém motivação e estimulo de amor á vida, o que representaria, força, animo, entusiasmo, vitalidade e outras (FERREIRA, 1986).

A QV passa por vários aspectos como trabalho, saúde, familia e na sociedade como um todo, como sendo um contexto muito importante para a vida do ser humano, abordaremos o contexto da QV relacionada com a saúde, como um dos fatores essenciais para encontrar condições necessarias para sobrevivencia com qualidade. Nessa articulação entre saúde, condições de sobrevivência, etilo de vida e qualidade de vida, pode-se identificar na saúde pública e na medicina social, o desenvolvimento da promoção da saúde como campo conceitual e de prática que busca explicações e respostas integradoras para uma vida com qualidade.

Não é raro se deparar com problemas e complicações decorrentes do estilo de vida dos indivíduos, podemos observar em todas as camadas sociais atingindo também diversos estágios da vida. Por conta disso, durante toda a vida, todas as pessoas necessitam água e ar puros, ambiente saudável, alimentação adequada, situações social, econômica e cultural favoráveis, prevenção de problemas específicos de saúde, assim como educação e informação.

Por isso a importância da avaliação da QV, para verificar como a saúde pode repercutir na vida dos indivíduos. Portanto, vale destacar aqui que QV e Saúde, são um instrumento sociológico, que predominantemente tem que ser mensurado, sendo assim, é de suma importancia discutirmos um pouco sobre o mesmo, seus indicadores e estatísticas para melhor compreenção da realidade em que vivemos.

Dessa forma, propusermos mencionar a importancia da avaliação da QV relacionada a saúde e os fatores socioeconômicos, em vista, para uma melhor compreenção de seus determinantes e 
indicadores. Existe atualmente, uma grande convergência no que diz respeito aos instrumentos, propostas para avaliar a QV, mas abordaremos somente dois, que são utilizados em diferentes contextos, mas com a mesma finalidade. O primeiro aborda que ele foi desenvolvido, para ser utilizado na área da saúde (paciente ou profissional de saúde) e o segundo é mais utilizado no contexto socioeconômico.

Para se melhorar realmente as condições de saúde de uma população, um objetivo social relevante em todas as sociedades, são necessárias mudanças profundas dos padrões econômicos no interior destas sociedades e intensificação de políticas sociais, que são eminentemente políticas públicas. Ou seja, para que uma sociedade conquiste saúde para todos os seus membros, são necessárias uma verdadeira ação inter-setorial e as chamadas políticas públicas saudáveis, isto é, políticas comprometidas com a qualidade de vida e a saúde da população.

É através de indicadores e estatísticas, e nao somente experiêcias de vida, que o cidadão é levado a perceber o verdadeiro cenario social no qual ele vive. Não importando em que padrão a QV esta se referindo, mas consequentemente induzem as decisões políticas, de saúde e sociais da humanidade. Ao descrevermos o contexto da QV e promoção da saúde, vimos à importância de relatar o papel da análise da sociedade e indicadores, na avaliação das situações de saúde, que engloba a descrição de perfis epidemiológicos, de qualidade de vida relacionada com a saúde e de condições socioeconômicas, atuais.

\section{Método}

O método utilizado para a realização do presente trabalho foi a revisão bibliográfica. Buscouse selecionar textos, artigos que servissem de base para as reflexões que nortearam o estudo.

Os procedimentos adotados foram: seleção do material nas bases de dados BIREME (Biblioteca Regional de Medicina), LILACS (Literatura Latino-americana e do Caribe em Ciências da Saúde), SCIELO (Scientific Electronic Library On-line), e USP: (Universidade de São Paulo), além de documentos disponíveis em sites do Ministério da Saúde (MS) e Organização das Nações Unidas (ONU).

Foram realizadas leituras dos artigos e textos, as quais nos possibilitou a seleção apenas daqueles que servissem de fundamentação para o estudo. Em seguida foram feitos os fichamentos devidos.

Id en line Revista de Psicologia. Ano 7, No. 20, Julho/2013 - ISSN 1981-1179

Edição eletrônica em http://idonline.emnuvens.com.br/id 
http://idonline.emnuvens.com.br/id

Foram selecionados 58 textos, à partir das palavras-chave: Qualidade de Vida, Promoção da Saúde, Indicadores de Qualidade de Vida, sendo utilizados 36 por se enquadrarem melhor nos propósitos do estudo.

\section{Qualidade de Vida}

\section{Aspectos históricos e conceituais.}

Para uma melhor compreensão da discussão sobre a qualidade de vida $(\mathrm{QV})$ relacionada à saúde, buscaremos aqui discutir, em primeira questão alguns conceitos sobre o que realmente trata e que significado tem para o entendimento científico e popular, quando abordamos o tema qualidade de vida.

Sempre houve, ao longo da história da humanidade, o mistério que envolve a existência do homem sobre a terra, a ordem de crescer, multiplicar-se e a de dominar a terra, isto é, de desvendar os segredos do universo no qual ele vive. As condições de vida em nosso planeta passam por contínuas transformações, decorrentes a isso, as alterações introduzidas na terra e as mudanças na maneira de viver, provocadas pelo progresso tecnológico, nem sempre favorecem a QV (FINKLER, 1994).

Completando isso, Silva (2008), afirma que as transformações ocorridas nas últimas décadas trazem mudanças agressivas no modo de vida, que se descortina a partir da cultura de uma determinada sociedade e das exigências por bens materiais e de consumo, e de estilos de vida que se estabelecem a partir dos comportamentos gerados pelas facilidades tecnológicas e hábitos diferentes dos estabelecidos pela natureza humana.

Cultura essa, que pode ser relatada através de Buss, Hartz e Minayo (2000), ao afirmarem que, a um modelo hegemônico que está a um passo de adquirir significado planetário. É o preconizado pelo mundo ocidental, urbanizado, rico, polarizado por certo número de valores, que poderiam ser assim resumidos: conforto, prazer, boa mesa, moda, utilidades domésticas, viagens, carro, televisão, telefone, computador, uso de tecnologias, e com isso diminuem o trabalho manual, consumo de arte e cultura, entre outras verdadeiras riquezas.

Por conta disso, podemos constatar que poucas são as pessoas que não tem nada a lamentar algum incômodo físico, psicológico, emocional ou espiritual. E decorrentes desse descompasso surge reações como a insatisfação, tédio, angústia, ansiedade, frustração, depressão, estresse entre outras, evidenciando assim, a deterioração da QV, em que vive o homem nos dias atuais.

Id en line Revista de Psicologia. Ano 7, No. 20, Julho/2013 - ISSN 1981-1179. 
Diante desta catastrófica realidade, pensadores de todas as índoles medicina, psicologia, teologia, filosofia, engenharia, agricultura, indústria, e até políticos etc., desenvolvem um esforço gigantesco, para atender o clamor geral, por melhores condições de vida (FINKLER, 1994).

Atualmente, uma situação qualquer, com características indesejáveis que precisam ser melhoradas são, muitas vezes, descritas com a expressão baixa QV. Já uma situação futura desejada, diferente e melhor que a atual, passa a ser descrita como uma situação como melhorar a QV. Melhorar de vida, ter uma vida boa, ter uma vida melhor, ter melhor QV são formas de expressar esse futuro diferente e melhor buscado por todos os seres humanos (BUOGO, 2003).

A origem do conceito QV é apresentada por Ostenfild (1994) apud Paschoal (2000, p.30), quando trás o pensamento aristotélico que diz, "a boa vida", é a vida mais desejável é a vida de acordo com a mais alta das virtudes. Neste sentido, intui-se que, a felicidade seria a melhor e a mais prazerosa de todas as coisas.

Ainda, sob esta mesma condição Buogo (2003), afirma que o ser humano busca constantemente a sua felicidade, ao longo dos tempos. Mas principalmente nas últimas décadas, a relação que o homem tem estabelecido com si mesmo, com os outros e com o restante da natureza na busca da felicidade ou do prazer, tem deteriorado de tal modo que condições para viver, com a poluição do ar e da água, má distribuição da renda e de outros recursos, fome, desaparecimento de etnias e de espécies animais e vegetais, tem prejudicado a sua sobrevivência.

Nordenfelt (1994) apud Paschoal (2000), traz a caracterização de um conceito de QV: a felicidade com a vida ou alegria de viver, afirma que, felicidade é uma espécie de bem estar, assim, a situação econômica de uma pessoa, suas relações familiares, sua situação profissional, tanto quanto seus recursos internos, particularmente a saúde, fazem parte de acontecimentos podendo influenciar o seu bem estar.

De acordo com Constantino (2007), o construto QV é um fenômeno abstrato, complexo e multidimensional para o qual não se encontrou um consenso, havendo muitas tendências de pesquisas, todas complementares entre si, somando-se aos já existentes, demonstrando que o assunto esta longe de ser esgotado.

Dantas, Malerbo e Sawada (2003), através de um estudo exploratório descritivo, analisando as produções científicas das universidades públicas do estado de São Paulo sobre QV, poderão constatar que somente a partir dos anos 80 que o tema passou a ter maior significado, no Brasil mais precisamente a partir da década de 90 .

Id en line Revista de Psicologia. Ano 7, No. 20, Julho/2013 - ISSN 1981-1179 


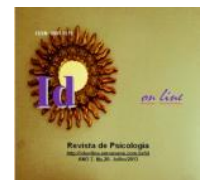

http://idonline.emnuvens.com.br/id

DOI: 10.14295/idonline.v7i20.235

Diante de tantos pensamentos, com o objetivo de melhor definir uma conceituação de QV, encontra-se também muitas divergências, mas apesar dessa dificuldade a literatura vem ao longo dos anos, descrevendo os objetivos, discussões e conclusões a respeito desse tema QV.

Mas o que é exatamente QV e qual seria o grau de prioridade em um país onde milhões de pessoas não têm suas necessidades básicas atendidas? Seria um luxo (requinte e sofisticação), e portanto, algo supérfluo diante de questões mais substantivas, como garantir um "patamar mínimo de dignidade e de condição humana" (HERCULANO, 1998).

Ainda, relativamente Herculano (1998, p.77-99), propõe que QV seja definida em um contexto mais amplo e global como sendo:

A soma das condições econômicas, ambientais, científico-culturais e políticas coletivamente construídas e postas à disposição dos indivíduos para que estes possam realizar suas potencialidades: inclui a acessibilidade à produção e ao consumo, aos meios para produzir cultura, ciência e arte, bem como pressupõe a existência de mecanismos de comunicação, de informação, de participação e de influência nos destinos coletivos, através da gestão territorial que assegure água e ar limpos, higidez ambiental, equipamentos coletivos urbanos, alimentos saudáveis e a disponibilidade de espaços naturais amenos urbanos, bem como da preservação de ecossistemas naturais.

Para Buss, Hartz e Minayo (2000), QV é uma noção eminentemente humana, quando o ser humano encontra o grau de satisfação na vida amorosa, familiar, social e ambiental ele esta tendo QV, sendo, portanto um termo que reflete muitas experiências e valores individuais e coletivos, em varias épocas, espaços e histórias diferentes, sendo, portanto, uma construção social e cultural.

Ressalta-se, Paschoal (2000), QV é um conceito de necessidade, ou mais especificamente, de preenchimento ou satisfação das necessidades. Pode-se afirma que a satisfação das necessidades resulta em alto grau de $\mathrm{QV}$, ou, um alto grau de QV leva as necessidades satisfeitas. Afirma que não há uma relação de causa-efeito, mas uma condição necessária, aonde, uma depende da outra.

Em 1995, Organização Mundial da Saúde (OMS) reuniu especialistas de varias partes do mundo e definiram QV como sendo "a percepção do individuo de sua posição na vida no contexto da cultura e sistema de valores nos quais ele vive e em relação aos objetivos, expectativas, padrões e preocupações". (FLECK, 2000, p.34). É um conceito amplo, ele inter-relaciona o meio ambiente com aspectos físicos, psicológicos, nível de independência, relações sociais e crenças pessoais.

A Física Quântica introduziu conceitos como níveis de realidade, descontinuidade, causalidade global e não-separatividade, que revelam uma interconexão global que afeta as condições para viver em um local qualquer e, conseqüentemente, pode afetar também a qualidade de vida de quem ali vive. Resgatando da Física Quântica a idéia de que nada existe fora da interação, porque nada existe sem o sentido do observador, Patrício (1999 apud Buogo, 2003, p.21) afirma:

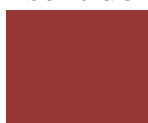

Id en line Revista de Psicologia. Ano 7, No. 20, Julho/2013 - ISSN 1981-1179.

Edição eletrônica em http://idonline.emnuvens.com.br/id 
Qualidade de Vida, enquanto produto e processo, diz respeito aos atributos e às propriedades que qualificam essa vida e ao sentido que tem para cada ser humano. Diz respeito às características do fenômeno vida, à como esta se apresenta, ao como se constrói, e como o indivíduo sente o constante movimento de tecer o processo de viver nas interações humanas (PATRÍCIO, 1999 apud BUOGO, 2003, p.21).

Buss, Hartz e Minayo (2000), conceituam QV como parâmetros subjetivos (valores não materiais) bem estar, felicidade, amor, prazer e objetivos (valores concretos) necessidades básicas, econômicas, sociais e culturais. Ainda neste caminho, Seidl e Zannon (2004), descreve que conceito de QV pode também, ser utilizado em duas vertentes, a primeira na linguagem cotidiana (por pessoas da população em geral), e a segunda no contexto da pesquisa cientifica.

No consentimento de Finkler (1994), a QV somente passa ter significado quando o homem encontra o seu equilíbrio psicológico, emocional e espiritual, aonde ele vai encontrar forças e clarividências para regular a sua vida de maneira a fazer com que ele tome iniciativa que promovam o seu bem estar.

Ao se retratar sobre QV, nao podemos também, deixar de descrever a declaração universal dos direitos humanos. Aonde descreve o mínimo necessário para que o ser humano leve uma vida digna, reconhecendo o direto para todos. Adotada e proclamada pela resolução 217 A (III) da Assembléia Geral das Nações Unidas em 10 de dezembro de 1948. Que diz:

\section{Art. $1^{\circ}$}

Todos os seres humanos nascem livres e iguais em dignidade e direitos. São dotados de razão e consciência e devem agir em relação uns aos outros com espírito de fraternidade.

\section{Art. $2^{\circ}$}

Todo ser humano tem direito a um padrão de vida capaz de assegurar a si e a sua família saúde e bem estar, inclusive alimentação, vestuário, habitação, cuidados médicos e os serviços sociais indispensáveis, e direito à segurança em caso de desemprego, doença, invalidez, viuvez, velhice ou outros casos de perda dos meios de subsistência fora de seu controle (BRASIL, 1998, p.1-4).

Embutido nesta afirmação Finkler (1994), o esforço pessoal e coletivo para melhorar a QV em nosso país, em nível de governo, de escola e de familia deve começar por atuar sobre as relações humanas. Sem esta providencia inicial, qualquer esforço para melhorar a QV pelo empenho político, na economia, na saúde pública, no trabalho, ocorre o risco de resultar em nada.

Admitindo, que uma boa QV seja uma conquista para cada indivíduo, o máximo que uma ação governamental poderia fazer é tão somente proporcionar condições que facilitem o viver de cada indivíduo. No caso de políticas públicas, a resposta à primeira questão poderia ser no sentido de que

Id en line Revista de Psicologia. Ano 7, No. 20, Julho/2013 - ISSN 1981-1179. 
elas, se bem executadas, contribuiriam fortemente para criar condições adequadas para viver e proporcionariam aos indivíduos por elas afetados a oportunidade de se revelarem com melhor ou pior qualidade de vida (BUOGO, 2003).

Resumindo, descreveu Constantino (2007), a QV tem como objetivo oferecer informações e estímulos para mudanças de hábitos dos indivíduos tem a estratégia principal à busca de um tripé que envolve conceitos da psicologia, da biologia e da sociologia (ser biopsicossocial), sendo por tanto, um equilíbrio das atividades cotidianas dos indivíduos, como cuidados de saúde, alimentação, atividade física, entre outros, ou seja, como estratégia principal o estilo de vida dos indivíduos.

Ainda neste caminho, Constantino (2007) descreve, estilo de vida é construir uma vida saudável é estar no mundo com o objetivo de bem viver. Compreender a importância de estilo de vida é agir em favor de uma saúde que se faz e se melhora a cada dia. É promover saúde, é participar na criação de políticas públicas saudáveis, sobretudo, é saber lidar com o mundo de uma forma positiva.

Dentro das questões mensionados anteriormente, abordaremos a seguir, a importancia da QV relacionada a saúde como um dos fatores primordiais para a busca de melhores condições de vida.

\section{Qualidade de vida relacionada á Saúde.}

Como foi descrito anteriormente, a QV passa por vários aspectos como trabalho, saúde, familia e na sociedade como um todo, como sendo um contexto muito importante para a vida do ser humano, abordaremos o contexto da QV relacionada com a saúde, como um dos fatores essenciais para encontrar condições necessarias para sobrevivencia com qualidade.

As mudanças econômicas, políticas, sociais e culturais, que ocorreram no mundo desde o século XIX e que se intensificaram no século passado, a saúde, sendo uma esfera da vida de homens e mulheres em toda sua diversidade e singularidade, não permaneceu fora do desenrolar das mudanças da sociedade nesse período. O processo de transformação da sociedade é também o processo de transformação da saúde e dos problemas sanitários. Nas últimas décadas, tornou-se mais e mais importante cuidar da vida de modo que se reduzisse a vulnerabilidade ao adoecer e as chances de que ele seja produtor de incapacidade, de sofrimento crônico e de morte prematura de indivíduos e população (BRASIL, 2006).

A saúde é reconhecida como um dos maiores valores na sociedade, sendo assim a OMS definiu saúde como um completo estado de bem-estar físico, mental e social e não meramente a ausência de doença. Uma resolução da $101^{\circ}$ sessão da assembléia mundial de saúde propôs uma

Id en line Revista de Psicologia. Ano 7, No. 20, Julho/2013 - ISSN 1981-1179.

Edição eletrônica em http://idonline.emnuvens.com.br/id 
modificação do conceito de saúde que desde então passou a ser, um estado dinâmico de completo bem-estar físico, mental, espiritual e social (WHO, 1946 apud FLECK, 2000).

A Lei Brasileira $\mathrm{n}^{\circ}$ 8.080, de 19 de setembro de 1990, diz:

\section{Art. $2^{\circ}$}

A saúde é um direito fundamental do ser humano, devendo o Estado prover as condições indispensáveis ao seu pleno exercício.

O dever do Estado de garantir a saúde consiste na reformulação e execução de políticas econômicas e sociais que visem à redução de riscos de doenças e de outros agravos no estabelecimento de condições que assegurem acesso universal e igualitário às ações e aos serviços para a sua promoção, proteção e recuperação.

\section{Art. $3^{\circ}$}

A saúde tem como fatores determinantes e condicionantes, entre outros, a alimentação, a moradia, o saneamento básico, o meio ambiente, o trabalho, a renda, a educação, o transporte, o lazer e o acesso aos bens e serviços essenciais; os níveis de saúde da população expressam a organização social e econômica do País (BRASIL, 1990).

De acordo com Buss (2000), a nova concepção de saúde importa uma visão afirmativa, que a identifica como bem-estar e qualidade de vida, e não simplesmente com ausência de doença. Segundo Dantas, Malerbo e Sawada (2003), atualmente a QV é tema de pesquisa imprescindível na área da saúde, visto que seus resultados devem contribuir de forma decisiva para aprovar e definir tratamentos.

O interesse pelo conceito QV na área da saúde, decorre, em parte, dos novos paradigmas que têm influenciado as políticas e as práticas do setor nas últimas décadas. Os determinantes e condicionantes do processo saúde-doença são multifatoriais e complexos. Assim, saúde e doença configuram processos compreendidos como um continuum, relacionamento entre os aspectos econômicos, socioculturais, à experiência pessoal e estilos de vida (SEIDL; ZANNON, 2004).

De acordo com Seidl e Zannon (2004), há indícios de que o termo QV relacionada com a saúde surgiu pela primeira vez na literatura médica na década de 30, segundo um levantamento de estudos que tinham por objetivo sua definição e que faziam referencia a avaliação da QV.

Para Buss, Hartz e Minayo (2000), a relação entre saúde e QV, existe desde o nascimento da medicina social, nos séculos XVIII e XIX, quando começaram a referendar esta tese e der importâncias para as políticas públicas e movimentos sociais.

Completando, Silva (2008) ao referir-se a definição á respeito da saúde e QV, como um determinante de que eles se relacionam a partir não só dos aspectos socioeconômicos, mas também do estilo de vida, que reflete ações habituais, valores, atitudes e oportunidades.

Constantino (2000), compreender a importância do estilo de vida para a saúde, é adotar uma vida saudável, adotando certos hábitos saudáveis como é o caso da atividade física e da alimentação saudável com o objetivo de bem viver, melhorando cada dia.

Id en line Revista de Psicologia. Ano 7, No. 20, Julho/2013 - ISSN 1981-1179.

Edição eletrônica em http://idonline.emnuvens.com.br/id 


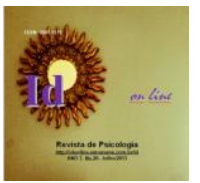

http://idonline.emnuvens.com.br/id

DOI: 10.14295/idonline.v7i20.235

Embutida nessa afirmação, A 57ª Assembleia-Geral da OMS, realizada em Maio de 2004, foi aprovada uma estratégia global relativamente a Alimentação, Atividade Física e Saúde, no âmbito da prevenção e controle das doenças não transmissíveis (BRASIL, 2004). Dessa estratégia destacam-se os seguintes pontos: a) Alimentação saudável: promover ações relativas à alimentação saudável visando à promoção da saúde e à segurança alimentar e nutricional; b) Prática corporal/atividade física: mapear e apoiar as ações de práticas corporais/atividade física existentes nos serviços de atenção básica e na Estratégia de Saúde da Família, e inserir naqueles em que não há ações; ofertar práticas corporais/atividade física como caminhadas, prescrição de exercícios, práticas lúdicas, esportivas e de lazer, na rede básica de saúde, voltadas tanto para a comunidade como um todo quanto para grupos vulneráveis; c) Prevenção e controle do tabagismo: sistematizar ações educativas e mobilizar ações legislativas e econômicas, de forma a criar um contexto que: reduza a aceitação social do tabagismo; d) Redução da morbimortalidade em decorrênciado uso abusivo de álcool e outras drogas: investimento em ações educativas e sensibilizadoras para crianças e adolescentes quanto ao uso abusivo de álcool e sensibilizar a população sobre os malefícios do uso abusivo do álcool; e) Prevenção da violência e estímulo à cultura de paz: ampliação e fortalecimento da Rede Nacional de Prevenção da Violência e Promoção da Saúde; f) Redução da morbimortalidade por acidentes de trânsito: promoção de discussões intersetoriais que incorporem ações educativas à grade curricular de todos os níveis de formação, articulação de agendas e instrumentos de planejamento, programação e avaliação, dos setores diretamente relacionados ao problema.

Para Constantino (2007), a meta da estratégia global é promover e proteger a saúde, orientando a criação de um segmento favorável para a adoção de medidas sustentáveis, a fim de reduzir a morbidade e a mortalidade e ainda é benefícios para a saúde publica no mundo todo. A aplicação dessa estratégia permitirá alcançar melhoras na saúde da população. Acredita ser possível realizar intervenções eficazes para possibilitar que as pessoas vivam mais e melhor, e assim, reduzir as desigualdades e promover o desenvolvimento.

Embutido nesta afirmação, Buss, Hartz e Minayo (2000), diz, o ambiente global influencia tanto o sistema de saúde como o estado de saúde dos indivíduos e coletivos, então nem todos os aspectos da vida humana, necessariamente, é uma questão médica ou sanitária. Portanto, são influenciados por setores econômicos, sociais e ambientais, desse modo, pode-se dizer que a questão da QV diz respeito ao padrão que a própria sociedade define, e o setor saúde ficando apenas com uma parcela das responsabilidades do modo e das condições de vida dos indivíduos.

Paralelamente Barcellos et al. (2002), diz que a análise das situações de saúde populacionais corresponde de acordo com as condições de vida de cada indivíduo, então, é dever dos sistemas locais

Id en line Revista de Psicologia. Ano 7, No. 20, Julho/2013 - ISSN 1981-1179.

Edição eletrônica em http://idonline.emnuvens.com.br/id

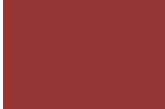


de saúde, verificarem a relação entre condições de vida, saúde e acesso aos serviços de saúde. Dependendo, portanto, de um processo de territorialização dos sistemas locais de saúde, para melhorar a QV da população.

No campo da Saúde Pública, os problemas são amenizados quando deslocamos nosso interesse nos problemas prioritários em saúde e nas ações, porque são elas que vão remover esses problemas. Para desenvolver políticas de saúde adequadas precisamos compreender as particularidades econômicas, sociais, ambientais e processos lógicos, que intervêm positiva ou negativamente na QV dessas populações e que influenciam, em face os diversos eventos da vida (PORTO; ROZEMBERG; UCHOA, 2002).

Da mesma forma, há muito tempo tem sido questionado o papel da medicina, da saúde pública e, num sentido mais genérico, do setor saúde no enfrentamento do que seriam as causas mais amplas e gerais dos problemas de saúde. Particularmente em países como o Brasil e outros da América Latina, esses problemas podem ser citados como a péssima distribuição de renda, o analfabetismo, baixo grau de escolaridade, assim como as condições precárias de habitação e ambiente. Entretanto, demonstrar que a qualidade/ condições de vida afeta a saúde e que esta influencia fortemente a qualidade de vida não é o único desafio (BUSS, 2000).

Nesse sentido, o estudo com relação saúde e QV evoca necessariamente uma articulação entre condições objetivamente definidas (estado de saúde, serviços e recursos disponíveis, bens, redes sociais de apoio) e o universo de representações (avaliação do estado de saúde, satisfação com os serviços, recursos, bens materiais e redes sociais de apoio), ou seja, entre as dimensões objetiva e subjetiva da existência (PORTO; ROZEMBERG; UCHOA, 2002).

Como se pode vê, os conceitos de QV relacionado à saúde passam por um momento de especial atenção, em geral, voltavam-se somente aos aspectos ligados á funcionalidade do individuo, e agora, enfatizam também os aspectos psicológicos e socioeconômicos da população, como influenciadores na determinação da QV em saúde (CONSTANTINO, 2007).

Segundo Buss (2000), existem evidências científicas abundantes que mostram a contribuição da saúde para a qualidade de vida de indivíduos ou populações. Da mesma forma, é sabido que muitos componentes da vida social que contribuem para uma vida com qualidade são também fundamentais para que indivíduos e populações alcancem um perfil elevado de saúde. Sendo assim, é necessário mais do que o acesso a serviços médicos-assistenciais de qualidade, é preciso enfrentar os determinantes da saúde em toda a sua amplitude, o que requer políticas públicas saudáveis, uma efetiva articulação intersetorial do poder público e a mobilização da população.

Id en line Revista de Psicologia. Ano 7, No. 20, Julho/2013 - ISSN 1981-1179. 


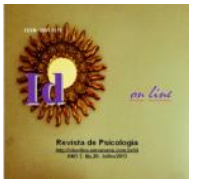

http://idonline.emnuvens.com.br/id

DOI: $10.14295 /$ idonline.v7i20.235

Nessa direção, o desafio colocado para o gestor federal do SUS consiste em propor uma política transversal, integrada e intersetorial, que faça dialogar as diversas áreas do setor sanitário, os outros setores do Governo, os setores privados e não-governamentais e a sociedade, compondo redes de compromisso e co-responsabilidade quanto à qualidade de vida da população em que todos sejam partícipes no cuidado com a saúde (BRASIL, 2006).

A saúde, como produção social de determinação múltipla e complexa, exige a participação ativa de todos os sujeitos envolvidos em sua produção - usuários, movimentos social, trabalhadores da Saúde, gestores do setor sanitário e de outros setores -, na análise e na formulação de ações que visem à melhoria da qualidade de vida. O paradigma promocional vem colocar a necessidade de que o processo de produção do conhecimento e das práticas no campo da Saúde e, mais ainda, no campo das políticas públicas faça-se por meio da construção e da gestão compartilhadas (BRASIL, 2006).

Políticas de saúde são baseadas no conceito de igualdade, de acesso e ou tratamento e sua referência sempre é construída a partir da ausência da doença. Ainda que sejam equitativas as ofertas ao acesso e cuidados de saúde, persistem as desigualdades relacionadas à estratificação social, chance de acesso aos recursos, oportunidades de conhecimento e ambiente de suporte que orientem os indivíduos ao comportamento saudável (SILVA, 2008).

Em resumo, na área da saúde, QV decorre em parte dos novos paradigmas, a melhoria da QV passou a ser um dos resultados esperados, tanto das praticas assistências quanto das políticas publicas para o setor nos campos da promoção da saúde e da prevenção de doenças (SCHUTTINGA, 1995 apud SEIDL; ZANNON, 2004).

$\mathrm{Na}$ articulação entre saúde, condições de sobrevivência, etilo de vida e qualidade de vida, pode-se identificar na saúde pública e na medicina social, o desenvolvimento da promoção da saúde como campo conceitual e de prática que busca explicações e respostas integradoras para uma vida com qualidade. É o que discutiremos a seguir.

\section{Qualidade de Vida e Promoção da saúde.}

Como podemos analisar anteriormente, a atenção à saúde tem investido na formulação, implementação e concretização de políticas de promoção, proteção e recuperação da saúde. Há, pois, um grande esforço na construção de um modelo de atenção à saúde que priorize ações de melhoria da qualidade de vida dos sujeitos e coletivos. (BRASIL, 2006).

Na base do processo de criação do SUS encontram-se:

Id en line Revista de Psicologia. Ano 7, No. 20, Julho/2013 - ISSN 1981-1179.

Edição eletrônica em http://idonline.emnuvens.com.br/id 
A necessidade de criar políticas públicas para promover a saúde, o imperativo da participação social na construção do sistema e das políticas de saúde e a impossibilidade do setor sanitário responder sozinho à transformação dos determinantes e condicionantes para garantir opções saudáveis para a população. Nesse sentido, o SUS, como política do Estado brasileiro pela melhoria da qualidade de vida e pela afirmação do direito à vida e à saúde, dialoga com as reflexões e os movimentos no âmbito da promoção da saúde. (BRASIL, 2006, p.6).

No SUS a estratégia de promoção da saúde é retomada como uma possibilidade de enfocar os aspectos que determinam o processo saúde-adoecimento em nosso país como, por exemplo: violência, desemprego, subemprego, falta de saneamento básico, habitação inadequada e/ou ausente, dificuldade de acesso à educação, fome, urbanização desordenada, qualidade do ar e da água ameaçada. (BRASIL, 2006).

Segundo Buss (2000), a promoção da saúde, vem sendo caracterizada nos últimos 20-25 anos, como uma estratégia importantíssima para enfrentar os múltiplos problemas de saúde que afetam as populações, de um lado, como reação à acentuada medicalização da vida social e, de outro, como uma resposta setorial articuladora de diversos recursos técnicos e posições ideológicas. Embora o termo tenha sido usado a princípio para caracterizar um nível de atenção da medicina preventiva seu significado foi mudando, passando a representar, mais recentemente, um enfoque político e técnico em torno do processo saúde-doença-cuidado.

A visão da intrínseca da relação entre condições de vida e qualidade de vida na saúde aproxima os clássicos da medicina social da discussão que, vem se revigorando na área, e tem no conceito de "promoção da saúde" sua estratégia central. (MINAYO; HARTZ; BUSS, 2000).

Para Gutierrez et al., ( apud Buss, 2000), promoção da saúde é o conjunto de atividades, processos e recursos, de ordem institucional, governamental ou da cidadania, orientados a propiciar:

A melhoria das condições de bem-estar e acesso a bens e serviços sociais, que favoreçam o desenvolvimento de conhecimentos, atitudes e comportamentos favoráveis ao cuidado da saúde e o desenvolvimento de estratégias que permitam à população maior controle sobre sua saúde e suas condições de vida, a níveis individuais e coletivos.

Segundo Sícoli e Nascimento (2003), promoção da saúde tem como objetivo, ampliar o campo de atuação da Saúde Pública, priorizando medidas preventivas e programas educativos que trabalha com mudanças comportamentais e de estilos de vida.

Sigerist (1946, apud Buss, 2000, p.166), foi um dos primeiros autores a referir o termo promoção da saúde, quando definiu as quatro tarefas essenciais da medicina:

Id en line Revista de Psicologia. Ano 7, No. 20, Julho/2013 - ISSN 1981-1179.

Edição eletrônica em http://idonline.emnuvens.com.br/id 
A promoção da saúde, a prevenção das doenças, a recuperação dos enfermos e a reabilitação, e afirmou que a saúde se promove proporcionando condições de vida decentes, boas condições de trabalho, educação, cultura física e formas de lazer e descanso.

Leavell e Clark (1976 apud Buss et al., 1998), utilizam o conceito de promoção da saúde ao desenvolverem o modelo da história natural da doença, a prevenção primária, a ser desenvolvida no período de pré-patogênese, consta de medidas destinadas a desenvolver uma saúde geral melhor, pela proteção específica do homem contra agentes patológicos ou pelo estabelecimento de barreiras contra os agentes do meio ambiente. A educação em saúde é elemento importante para esse objetivo.

As diversas conceituações disponíveis para a promoção da saúde podem ser reunidas em dois grandes grupos. Primeiro grupo caracteriza-se pelos estilos de vida dos indivíduos, neste caso, tendem a concentrar- se em componentes educativos, por exemplo, o hábito de fumar, a dieta, as atividades físicas, a direção perigosa no trânsito. Nessa abordagem, estão relacionados os riscos comportamentais passíveis de mudanças, sob o controle dos próprios indivíduos (SUTHERLAND; FULTON, 1992 apud BUSS, 2000).

Segundo grupo, este se sustenta no entendimento que a saúde é produto de amplo fatores relacionados com a qualidade de vida, incluindo um padrão adequado de nutrição, habitação e saneamento, boas condições de trabalho, oportunidades de educação, apoio social para famílias e indivíduos, estilo de vida responsável, e cuidados de saúde. Suas atividades estariam, então, mais voltadas ao coletivo de indivíduos e ao ambiente (SUTHERLAND; FULTON, 1992 apud BUSS, 2000).

Para Buss, Hartz e Minayo (2000), o conceito de promoção de Saúde é o foco mais relevante da avaliação da QV no âmbito da saúde, centrando-se na capacidade de viver sem doenças ou de superar as dificuldades dos estados ou condições de morbidade. No entanto, os autores fazem uma crítica a essas avaliações, pois, apesar de reconhecer que muitos determinantes de QV se situam em outros setores (que não á saúde), o sistema de saúde não intervém sobre eles.

Intimamente relacionada à vigilância à saúde e a um movimento de crítica à medicalização do setor, a promoção de saúde supõe uma concepção que não restrinja a saúde à ausência de doença, mas que seja capaz de atuar sobre seus determinantes. Incidindo sobre as condições de vida da população, supondo ações intersetoriais que envolvam a educação, o saneamento básico, a habitação, a renda, o trabalho, a alimentação, o meio ambiente, o acesso a bens e serviços essenciais, o lazer, entre outros determinantes sociais da saúde (SÍCOLI; NASCIMENTO, 2003).

Buss (2000, p.166), afirma que:

Id en line Revista de Psicologia. Ano 7, No. 20, Julho/2013 - ISSN 1981-1179 
Os procedimentos para a promoção da saúde incluem um bom padrão de nutrição, ajustado às várias fases do desenvolvimento humano; o atendimento das necessidades para o desenvolvimento ótimo da personalidade, incluindo o aconselhamento $\mathrm{e}$ educação adequados dos pais, em atividades individuais ou de grupos; educação sexual e aconselhamento pré-nupcial; moradia adequada; recreação e condições agradáveis no lar e no trabalho. A orientação sanitária nos exames de saúde periódicos e o aconselhamento para a saúde em qualquer oportunidade de contato entre o médico e o paciente, com extensão ao resto da família, estão entre os componentes da promoção.

A promoção à saúde desponta como nova concepção de saúde internacional em meados dos anos 70, na década anterior foi discutido a determinação social e econômica da saúde e a construção de uma concepção não centrada na doença. Nesse sentido, apontam-se dois acontecimentos importantes: a abertura da China Nacionalista ao mundo exterior, com duas missões de observação de especialistas ocidentais da OMS em 1973-1974, e o movimento canadense desenvolvido a partir do Relatório Lalonde: uma nova perspectiva na saúde dos canadenses em 1974 (BRASIL, 2002).

Reforçando esta afirmativa Buss (1998), os sistemas de saúde começam a ter significado nos países de primeiro mundo a partir da década de 70, tendo como pano de fundo novas concepções do processo saúde-enfermidade-cuidado. Como modelos de lalonde 1974, Blum, 1979 e Dever, 1980 que procuraram articular quatro dimensões explicativas : biologia humana, estilos de vida, ambiente e serviços de saúde. Com a má utilização de mecanismos de regulação cada vez mais custosos e sofisticados, os sistemas de saúde continuam ineficazes, a partir disso com a divulgação do documento Informe Lalonde que teve motivação política, técnica e econômica para enfrentar os aumentos dos custos da saúde.

As repercussões do Relatório Lalonde podem ser identificadas na concepção orientadora das práticas de promoção de saúde ao longo da década de 1970 que, em sua maioria, tiveram seu foco restrito à modificação de hábitos, estilos de vida e comportamentos individuais não saudáveis, entre os quais o fumo, a obesidade, a promiscuidade sexual e o abuso de substâncias psicoativas. Tal abordagem centrava-se na prevenção de doenças crônico-degenerativas, problema prioritário nos países desenvolvidos (SÍCOLI; NASCIMENTO, 2003).

O Informe Lalonde influenciou as políticas sanitárias de outros países como, na Conferência Internacional de Cuidados Primários de Saúde de Alma Ata, em 1978, com a proposta de Saúde para Todos no ano 2000 e a Estratégia de Atenção Primária de Saúde. Assim, em meados dos anos 80, começa a surgir um discurso alternativo de promoção e, em 1984, a OMS/Europa produziu um documento preliminar contendo os elementos-chave da nova promoção à saúde, reforçando a noção da determinação social da saúde. Em 1986, em Ottawa/Canadá sob os auspícios da OMS, do MS e do

Id en line Revista de Psicologia. Ano 7, No. 20, Julho/2013 - ISSN 1981-1179.

Edição eletrônica em http://idonline.emnuvens.com.br/id 
Bem Estar do Canadá realizou a I conferencia Internacional sobre Promoção da Saúde (HEIDMANN et al., 2006).

A carta de Ottawa assume o conceito de saúde da OMS e define como:

A saúde deve ser vista como um recurso para a vida, e não como objetivo de viver. Nesse sentido, a saúde é um conceito positivo, que enfatiza os recursos sociais e pessoais, bem como as capacidades físicas. Assim, a promoção da saúde não é responsabilidade exclusiva do setor saúde, e vai para além de um estilo de vida saudável, na direção de um bem-estar global (BRASIL, 2002, p.19).

A carta de Ottawa define promoção da saúde como:

O processo de capacitação da comunidade para atuar na melhoria de sua qualidade de vida e saúde, incluindo uma maior participação no controle deste processo. Para atingir um estado de completo bem-estar físico, mental e social os indivíduos e grupos devem saber identificar aspirações, satisfazer necessidades e modificar favoravelmente o meio ambiente (BRASIL, 2002, p.19).

Segundo Buss (1998), carta de Ottawa aponta para os determinantes múltiplos da saúde e para intersetorialidade. E completa, afirmando que as condições e os recursos fundamentais para a saúde são paz, habitação, educação, alimentação, renda, ecossistema estável, recursos sustentáveis, justiça social e eqüidade.

Dentre os campos de ação da promoção de saúde mencionados na Carta de Ottawa estão o estabelecimento de políticas públicas favoráveis à saúde, a criação de ambientes propícios, o fortalecimento da ação comunitária, o desenvolvimento de habilidades pessoais e a reorientação dos serviços sanitários (SÍCOLI; NASCIMENTO, 2003).

A $2^{\text {a }}$ Conferência Internacional sobre Promoção de Saúde, realizada em Adelaide (Austrália) em 1988, enfatizou a elaboração de políticas públicas saudáveis, caracterizadas pelo interesse e preocupação explícitos de todas as áreas das políticas públicas em relação à saúde e à eqüidade, e pelos compromissos com o impacto de tais políticas sobre a saúde da população. Identificou quatro áreas prioritárias para promover ações imediatas em políticas públicas saudáveis: apoio à saúde da mulher; alimentação e nutrição; tabaco e álcool; criação de ambientes favoráveis (BRASIL, 2001 apud SÍCOLI; NASCIMENTO, 2003).

A $3^{\text {a }}$ Conferência Internacional realizada em Sundsvall (Suíça), em 1991, enfoca a criação de ambientes favoráveis à saúde: este conclave evidencia a situação de extrema pobreza e privação, em um ambiente de risco a milhares de pessoas no planeta. Propõe ambientes físicos, sociais, econômicos e políticos mais favoráveis à saúde. Ressalta que, para promover este ambiente favorável à saúde, é preciso englobar quatro aspectos importantes: a dimensão social; a dimensão política; a dimensão

Id en line Revista de Psicologia. Ano 7, No. 20, Julho/2013 - ISSN 1981-1179.

Edição eletrônica em http://idonline.emnuvens.com.br/id

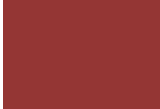


econômica e a necessidade de reconhecer e utilizar a capacidade e o conhecimento das mulheres em todos os setores, inclusive o político e o econômico (HEIDMANN et al., 2006).

A Declaração de Jacarta, fruto da $4^{a}$ Conferência Internacional sobre Promoção de Saúde, realizada na Indonésia, em 1997, enfatiza o surgimento de novos determinantes da saúde. Destaca que a promoção à saúde deve ser realizada em conjunto com a população, é necessário que as pessoas tenham direito de voz e mais acesso ao processo de tomada de decisão (BUSS et al., 1998).

A $5^{\text {a }}$ Conferência Mundial, realizada no México, em 2000, procurou avançar no desenvolvimento das prioridades da promoção de saúde para o século XXI identificadas em Jacarta e confirmadas pela Assembléia Mundial da Saúde de 1998: (BRASIL, 2001 apud SíCOLI; NASCIMENTO, 2003).

a) promover a responsabilidade social em matéria de saúde;

b) ampliar a capacitação das comunidades e dos indivíduos;

c) aumentar a "inversão" no desenvolvimento da saúde;

d) assegurar a infra-estrutura necessária à promoção de saúde e fortalecer sua base científica;

e) reorientar os sistemas e serviços de saúde.

A $6^{\text {a }}$ Conferência Mundial de Promoção à Saúde A Carta de Bangkok: foi realizada na cidade de Bangkok (Tailândia), em agosto de 2005. Reforça as mudanças no contexto da saúde global, incluindo o crescimento das doenças transmissíveis e crônicas, no qual incluem as doenças cardíacas, câncer e diabetes. Procura dar uma nova direção para a Promoção à Saúde, buscando alcançar saúde para todos através de quatro compromissos: desenvolvimento da agenda global, responsabilidade de todos os governos, meta principal da comunidade e da sociedade civil, necessidade para boa administração prática. (HEIDMANN et al., 2006).

As Conferências Regionais, Sub-regionais e Específicas de Promoção à Saúde, enfatizadas a seguir, foram elaboradas para discutir problemas específicos dos países latino-americanos ou determinados países, sempre incorporando as tendências e experiências internacionais da promoção à saúde de outras regiões do mundo. (HEIDMANN et al., 2006).

1) Declaração de Santa-Fé de Bogotá (1992)

2) Carta do Caribe - I Conferência de Promoção da Saúde do Caribe (1993)

3) Promoção à Saúde da População no Canadá (1996)

4) Rede de Megapaíses para a Promoção da Saúde Genebra, Suíça (1998)

O Ministério da Saúde na portaria 687 de 30 de dezembro de 2006 com criação da Política Nacional de Promoção da Saúde, num esforço para o enfrentamento dos desafios da produção de

Id en line Revista de Psicologia. Ano 7, No. 20, Julho/2013 - ISSN 1981-1179.

Edição eletrônica em http://idonline.emnuvens.com.br/id 
saúde, tem como objetivo: Promover a qualidade de vida e reduzir vulnerabilidade e riscos à saúde relacionados aos seus determinantes e condicionantes - modos de viver, condições de trabalho, habitação, ambiente, educação, lazer, cultura, acesso a bens e serviços essenciais.

I - Incorporar e implementar ações de promoção da saúde, com ênfase na atenção básica.

II - Ampliar a autonomia e a co-responsabilidade de sujeitos e coletividades, inclusive o poder público, no cuidado integral à saúde e minimizar e/ou extinguir as desigualdades de toda e qualquer ordem (étnica, racial, social, regional, de gênero, de orientação/opção sexual, entre outras).

III - Promover o entendimento da concepção ampliada de saúde, entre os trabalhadores de saúde, tanto das atividades-meio, como os da atividades-fim.

IV - Contribuir para o aumento da resolubilidade do Sistema, garantindo qualidade, eficácia, eficiência e segurança das ações de promoção da saúde.

$\mathrm{V}$ - Estimular alternativas inovadoras e socialmente inclusivas/contributivas no âmbito das ações de promoção da saúde.

VI - Valorizar e otimizar o uso dos espaços públicos de convivência e de produção de saúde para o desenvolvimento das ações de promoção da saúde.

VII - Favorecer a preservação do meio ambiente e a promoção de ambientes mais seguros e saudáveis.

VIII - Contribuir para elaboração e implementação de políticas públicas integradas que visem à melhoria da qualidade de vida no planejamento de espaços urbanos e rurais.

IX - Ampliar os processos de integração baseados na cooperação, solidariedade e gestão democrática;

X - Prevenir fatores determinantes e/ou condicionantes de doenças e agravos à saúde. XI Estimular a adoção de modos de viver não-violentos e o desenvolvimento de uma cultura de paz no País.

XII - Valorizar e ampliar a cooperação do setor Saúde com outras áreas de governos, setores e atores sociais para a gestão de políticas públicas e a criação e/ou o fortalecimento de iniciativas que signifiquem redução das situações de desigualdade.

\section{Diretrizes}

I - Reconhecer na promoção da saúde uma parte fundamental da busca da eqüidade, da melhoria da qualidade de vida e de saúde.

II - Estimular as ações intersetoriais, buscando parcerias que propiciem o desenvolvimento integral das ações de promoção da saúde.

Id en line Revista de Psicologia. Ano 7, No. 20, Julho/2013 - ISSN 1981-1179.

Edição eletrônica em http://idonline.emnuvens.com.br/id 
III - Fortalecer a participação social como fundamental na consecução de resultados de promoção da saúde, em especial a eqüidade e o empoderamento individual e comunitário.

IV - Promover mudanças na cultura organizacional, com vistas à adoção de práticas horizontais de gestão e estabelecimento de redes de cooperação intersetoriais.

V - Incentivar a pesquisa em promoção da saúde, avaliando eficiência, eficácia, efetividade e segurança das ações prestadas.

VI - Divulgar e informar das iniciativas voltadas para a promoção da saúde para profissionais de saúde, gestores e usuários do SUS, considerando metodologias participativas e o saber popular e tradicional.

A OMS caracteriza como iniciativas de promoção de saúde, os programas, as políticas e as atividades planejadas e executadas de acordo com os seguintes princípios: concepção holística, intersetorialidade, empoderamento, participação social, eqüidade, ações multi-estratégicas e sustentabilidade (WHO, 1998 apud SÍCOLI; NASCIMENTO, 2003).

No debate sobre promoção da saúde e qualidade de vida, um especial destaque deve ser dado ao tema das políticas públicas saudáveis, da governabilidade, da gestão social integrada, da intersetorialidade, das estratégias dos municípios saudáveis e do desenvolvimento local. No nosso entendimento, estes são mecanismos operacionais concretos para a implementação da estratégia da promoção da saúde e da qualidade de vida (BUSS, 2000).

Entende-se que a promoção da saúde apresenta-se como um mecanismo de fortalecimento e implantação de uma política transversal, integrada e intersetorial, que faça dialogar as diversas áreas do setor sanitário, os outros setores do Governo, o setor privado e não-governamental, e a sociedade, compondo redes de compromisso e co-responsabilidade quanto à qualidade de vida da população em que todos sejam partícipes na proteção e no cuidado com a vida (BRASIL, 2006).

Sinteticamente, a idéia moderna de políticas públicas saudáveis envolve um duplo compromisso: o compromisso político de situar a saúde no topo da agenda pública, promovendo-a de setor da administração a critério de governo, e o compromisso técnico de enfatizar, como foco de intervenção, os fatores determinantes do processo saúde-doença (BUSS, 2000).

No desenvolvimento de políticas de promoção de saúde, deve haver contínua consulta, diálogo e troca de idéias entre indivíduos e grupos, tanto leigos como profissionais. Mecanismos políticos devem ser estabelecidos de forma a garantir oportunidades de expressão e desenvolvimento do interesse público na saúde, $\mathrm{O}$ empoderamento e a participação social são destacados como princípios chave, sendo a efetiva e concreta participação social estabelecida como objetivo essencial da promoção de saúde (WHO, 1984 apud SíCOLI; NASCIMENTO, 2003).

Id en line Revista de Psicologia. Ano 7, No. 20, Julho/2013 - ISSN 1981-1179. 
http://idonline.emnuvens.com.br/id

Segundo Sícoli e Nascimento (2003), a nova promoção de saúde se propõe a enfocar os determinantes gerais, isto é, os sócio-ambientais e econômicos, atuando sobre as condições de vida cotidianas e sendo direcionada ao coletivo e à defesa dos direitos sociais. Trata-se, portanto, de um processo de fomento ao compromisso político (dos gestores e sociedade civil) e de impulsão às mudanças sociais.

É importante compreender, que a promoção à saúde pode trazer contribuições relevantes, para romper com a hegemonia do modelo biomédico. É necessário intensificar as ações das estratégias de promoção no cotidiano dos serviços de saúde, promover a autonomia das pessoas, indivíduos e profissionais, para que em conjunto possam compreender a saúde como resultante das condições de vida e propiciar um desenvolvimento social mais eqüitativo (HEIDMANN, 2006).

De acordo Barcellos et al. (2002), uma das questões importantes para o diagnóstico de situações de saúde, nesse sentido, é o desenvolvimento de indicadores capazes de detectar e refletir condições de risco à saúde advinda de condições econômicas, ambientais e sociais adversas, da população.

Como podemos compreender não é raro se deparar com problemas e complicações decorrentes do estilo de vida dos indivíduos, podemos observar em todas as camadas sociais atingindo também diversos estágios da vida. Por isso a importância da avaliação da QV, para verificar como a saúde pode repercutir na vida dos indivíduos. Portanto, vale destacar aqui que QV, é um instrumento sociológico, que predominantemente tem que ser mensurado, sendo assim, é de suma importancia discutirmos um pouco sobre o mesmo, seus indicadores, e organização, para melhor compreenção da realidade em que vivemos.

\section{Considerações Finais}

Os modos de viver têm sido abordados numa perspectiva fragmentária, e colocam os sujeitos e as comunidades como os únicos responsáveis pelas várias mudanças ocorridas no processo saúdeadoecimento ao longo da história.

Contudo, na perspectiva ampliada de QV e Saúde, como definida no âmbito do movimento da Reforma Sanitária brasileira, do SUS e das Cartas de Promoção da Saúde, os modos de viver não se referem apenas ao exercício da vontade ou liberdade individual e comunitária.

Ao contrário, os modos como sujeitos e coletividades elegem determinadas opções de viver como desejáveis, organizam suas escolhas e criam novas possibilidades para satisfazer suas

Id en line Revista de Psicologia. Ano 7, No. 20, Julho/2013 - ISSN 1981-1179.

Edição eletrônica em http://idonline.emnuvens.com.br/id 
necessidades, desejos e interesses pertencentes à ordem coletiva, uma vez que seu processo de construção se dá no contexto da própria vida.

No esforço por garantir os princípios do SUS e a constante melhoria dos serviços por ele prestados, e por melhorar a qualidade de vida de sujeitos e coletividades, entende-se que é urgente superar a cultura administrativa fragmentada e desfocada dos interesses e das necessidades da sociedade, evitando o desperdício de recursos públicos, reduzindo a superposição de ações e, conseqüentemente, aumentando a eficiência e a efetividade das políticas públicas existentes.

Espera-se, contudo, que a avaliação da QV, contribuam para aprofundar os conhecimentos dessa temática e por meio de sua aplicação provoque evolução da promoção da saúde e da qualidade de vida.

Se cada pessoa se preocupar em desenvolver um padrão comportamental favorável à sua saúde e lutar para que as condições sociais e econômicas sejam favoráveis à qualidade de vida e à saúde de todos, certamente estará dando uma poderosa contribuição para que tenhamos uma população mais saudável, com vida mais longa e prazerosa.

Sendo assim, a atuação dos profissionais da saúde, especificamente dos enfermeiros, é de grande importância, podendo resultar em ações locais, com impacto regional, nacional e internacional. Desta forma, os enfermeiros, na academia e na assistência, empreendem esforços para atender às populações mais carentes e excluídas visando garantir a integralidade do cuidado. Em meio às inúmeras dificuldades, derivadas de fatores políticos, econômicos, sociais e culturais, os enfermeiros devem continuar lutando pela qualidade de vida dos indivíduos, atuando como agentes multiplicadores do conhecimento e de ações humanizadas e mobilizando atividades conjuntas da sociedade civil e do Estado

\section{Referências}

BARCELLOS C.C. et al. Organização espacial, saúde e qualidade de vida: análise espacial e uso de indicadores na avaliação de situações de saúde. Informe Epidemiológico do SUS, Rio de Janeiro, v.11, n.3, p.129-138, 2002. Disponível em: http://scielo.iec.pa.gov.br/scielo.php?

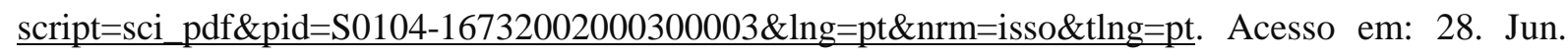
2008. 
BRASIL, 57 Assembléia Mundial de Saúde, de 22 de maio de 2004. Estratégia Global em Alimentação Saudável, Atividade Física e Saúde. Estratégia Global da OMS para Alimentação e Nutrição, Brasília, DF, p.26, 2004.

BRASIL, Lei $\mathbf{n}^{\mathbf{0}}$ 8.080, de 19 de Setembro de 1990. Dispõe sobre as condições para a promoção, proteção e recuperação da saúde, a organização e o funcionamento dos serviços correspondentes e dá outras providências, Brasília, DF, p.19, 1990.

BRASIL, Ministério da Saúde. Secretaria de Políticas de Saúde. Projeto Promoção da Saúde. As Cartas da Promoção da Saúde, Brasília, DF, p.56, 2002.

BRASIL, Ministério da Saúde. Secretaria de Vigilância em Saúde. Secretaria de Atenção à Saúde. Política nacional de promoção da saúde, Brasília, DF, $1^{\text {a }}$ ed, p.60, 2006.

BRASIL, Unesco, 10 de dezembro de 1948. Declaração Universal dos Direitos Humanos. Adotada e proclamada pela resolução 217 A (III) da Assembléia Geral das Nações Unidas, Brasília, DF, p.6, 1998.

BUOGO, G. Qualidade de vida e de condições para viver: entre a compreensão e a medida. Dissertação (Mestrado em Agroecossistemas) - Centro de Ciências Agrárias, Universidade Federal de Santa Catarina. Florianópolis, p.79, 2003.

BUSS, P.M. et al. Promoção da saúde e a saúde publica: contribuição para o debate entre as escolas de saúde publica da America Latina. Rio de janeiro, 1998.

BUSS, P.M. Globalização, pobreza e saúde. Ciência e Saúde Coletiva, Rio de Janeiro, v.12, n.6, p.1575-1589, 2007. Disponível em: $\quad$ http://www.scielosp.org/scielo. php?script=sci_arttext\&pid=S141381232007000600019. Acesso em: 10. Jan. 2009.

BUSS, P.M. Promoção da saúde e qualidade de vida. Ciência e Saúde Coletiva, Rio de Janeiro, v.5, n.1, p.163-177, 2000. Disponivel em: $\quad$ http://www.scielosp.org/scielo. php?pid=S141381232000000100014\&script=sci arttext. Acesso em: 05. Jan. 2009. 
CONSTANTINO, M.A.C. Avaliação da qualidade de vida: desenvolvimento e validação de um instrumento, por meio de indicadores biopsicossociais, junto á comunidade da universidade de são Paulo - USP, 2007. Dissertação (tese de doutorado) - programa de nutrição humana aplicada universidade de são Paulo, São Paulo, p.163, 2007.

DANTAS, R.A.S.; SAWADA, N.O.; MALERBO, M.B. Pesquisas sobre qualidade de vida: uma revisão da produção científica das universidades públicas do estado de São Paulo. Revista Latino Americana de Enfermagem, Ribeirão Preto, v.11, n.4, p.532-538, 2003. Disponível em: http://www.revistasusp.sibi.usp.br/scielo.php?script=sci_arttext\&pid= S010411692003000400017\&lng=pt\&nrm=isso. Acesso em: 05. Abr. 2008.

FERREIRA, A.B.H. Novo Dicionário Aurélio da Língua Portuguesa. 2.ed. Rio de Janeiro: Editora Nova Fronteira, p.1.838, 1986.

FINKLER, P. Qualidade de vida e plenitude humana. Petrópolis: Vozes, p.142, 1994.

FLECK, M.P.A. et al. Aplicação da versão em português do instrumento abreviado de avaliação da qualidade de vida (WHOQOL-bref). Revista de Saúde Pública, v.34, n.2, p.178-183, 2000. Disponível em: $\quad$ http://www.scielosp.org/scielo.php?script=sci_arttext\&pid=S00348910 2000000200012. Acesso em: 10 abr. 2008.

FLECK, M.P.A. O instrumento de avaliação de qualidade de vida da organização mundial da saúde (WHOQOL-100): características e perspectivas. Ciência e Saúde Coletiva, v.5, n.1, p.33-38, 2000. Disponível em: http://www.scielo.br/scielo.php?script=sci

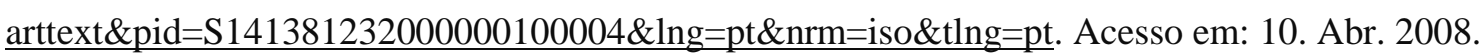

HEIDMANN, I.T.S.B. et al. Promoção a saúde: trajetória histórica de suas concepções. Texto e Contexto - Enfermagem, v.15, n.2, p.352-358, 2006. Disponível em: http://www.scielo.br/scielo.php?pid=S010407072006000200021\&script=sci_arttext\&tlng=pt. Acesso em: 06. Jan. 2009.

HERCULANO, S.C. A qualidade de vida e seus indicadores (Publicado no livro Qualidade de vida e riscos ambientais, Selene Herculano et al. (org.). Niterói: 2000.

Id en line Revista de Psicologia. Ano 7, No. 20, Julho/2013 - ISSN 1981-1179. Edição eletrônica em http://idonline.emnuvens.com.br/id 
MINAYO, M.C.S.; HARTZ, Z. M. A.; BUSS, P. M. Qualidade de vida e saúde: um debate necessário. Ciência e Saúde Coletiva, v.5, n.1, p.7-18, 2000.

MOREL, C.M. A pesquisa em saúde e os objetivos do milênio: desafios e oportunidades globais, soluções e políticas nacionais. Ciência Saúde Coletiva, v.9, n.2, p.261-270, 2004. Disponível em: http://www.scielosp.org/scielo.php?pid=S141381232004000200002\&script=sci_arttext\&tlng. Acesso em: 20. Jan. 2009.

PASCHOAL S.M.P. Qualidade de vida do idoso: elaboração de um instrumento que privilegie sua opinião. Dissertação (mestrado em medicina) - faculdade de medicina, universidade de São Paulo, São Paulo, p.255, 2000.

SEIDL, E.M.F.; ZANNON, C.M.L.C. Qualidade de vida e saúde: aspectos conceituais e metodológicos. Cadernos de Saúde Pública, v.20, n.2, p.580-588, 2004.

SICOLI, J.L.; NASCIMENTO, P.R. Promoção de saúde: concepções, princípios e operacionalização. Interface Comunicação, Saúde e Educação, Botucatu, v.7, n.12, p.101-122, 2003.

SILVA, T.T.R. Estratégias organizacionais para a promoção de saúde e qualidade de vida: avaliando a qualidade de vida no trabalho. 2007. Dissertação (Mestrado em Educação Física) Faculdade de Educação Física. Universidade Estadual de Campinas, Campinas, p.75, 2007.

UCHOA, E.; ROZEMBERG, B.; PORTO, M.F.S. Entre a fragmentação e a integração: saúde e qualidade de vida de grupos populacionais específicos. Informe Epidemiológico do SUS, Rio de Janeiro, v.11, n.3, p.115-128, 2002. Disponível em: http://scielo.iec.pa.gov.br/scielo.php?script=sci _abstract\&pid=S010416732002000300002\&lng=es\&nrm=iso\&tlng=en. Acesso em: 15.Jan.2010.

\section{Como citar este artigo (Formato ISO):}

LEITE, P.N.B. Qualidade de vida e promoção da saúde. Id on Line Revista de Psicologia, Julho de 2013, vol.1, n.20, p. 33-56. ISSN 1981-1189.

Id en line Revista de Psicologia. Ano 7, No. 20, Julho/2013 - ISSN 1981-1179. 